\title{
Unexplained diarrhoea and failure to thrive in 2 siblings with unusual facies and abnormal scalp hair shafts: a new syndrome
}

\author{
LESLIE STANKLER, DAVID LLOYD, RODNEY J POLLITT, ELIZABETH S GRAY, \\ HAZEL THOM, AND GEORGE RUSSELL
}

Department of Dermatology, Royal Aberdeen Children's Hospital; Department of Child Health, University of Aberdeen; Department of Psychiatry, Middlewood Hospital, Sheffield; Department of Pathology and Department of Child Health, University of Aberdeen

SUMMARY A family is described in which 2 siblings born to healthy parents presented with abnormal facies, persistent diarrhoea, and early death. Exhaustive pathological and biochemical investigations failed to find a cause. The scalp hair of both babies had an abnormal amino-acid composition, and presented an appearance that was unique on scanning electron microscopical examination; this fact and the clinical picture probably represents a new syndrome.

Structural and biochemical abnormalities of scalp hair have been reported in association with various nutritional and biochemical defects in children. ${ }^{1} \mathrm{We}$ report hair abnormalities in 2 siblings with unusual facies who died after prolonged periods of persistent diarrhoea with failure to thrive.

\section{Case reports}

The children were the second and third offspring of healthy unrelated parents. The father had been born in 1945 and the mother in 1948. Both had normal karyotypes and negative serological tests for syphilis. The mother's blood group was $\mathrm{A}$ Rhnegative and she had received anti-D globulin after each of her first two pregnancies. Her menstrual cycle was irregular and low oestriol levels were noted during all her pregnancies. The first pregnancy produced a stillborn $820-\mathrm{g}$ anencephalic infant of indeterminate sex with severe spinal rachischisis. The placenta weighed $320 \mathrm{~g}$. A postpartum intravenous glucose tolerance test was normal.

Case 1. The second pregnancy ended in 1973 in the spontaneous delivery of a girl who weighed $1680 \mathrm{~g}$ at a gestational age estimated clinically and radiologically to be 38 weeks. There was no birth asphyxia. The abnormal findings are listed in the Table. The baby's clinical course was uneventful until day 6 when the perineum appeared excoriated. Urinary examination at this time showed the presence of

\section{Table Clinical features}

\begin{tabular}{lcc}
\hline & Case 1 & Case 2 \\
\hline Meconium staining of amniotic fluid & + & + \\
Placental weight (g) & 560 & 880 \\
Light-for-date & + & + \\
Large, low-set, simple ears & + & + \\
Prominent eyes with shallow supraorbital ridges & + & + \\
Antimongoloid slanting eyes & + & 0 \\
Flat broad nose & + & + \\
Large mouth & + & + \\
Cleft uvula & + & 0 \\
Excoriated buttocks (before start of diarrhoea) & + & + \\
Woolly, easily removed black hair showing & + & + \\
$\quad$ trichorrhexis blastysis & + & + \\
Rubbery skin & + & + \\
Failure to thrive & + & + \\
Diarrhoea developing in third week & + & + \\
Thermoregulatory problems & 0 & + \\
Palpable spleen & + & + \\
Normal karyotype & + & + \\
Galactosuria without galactosaemia & + & + \\
Hepatic cirrhosis and haemosiderosis & 0 & + \\
Renal cortical microcysts & + & + \\
Islet cell hyperplasia & & + \\
\hline
\end{tabular}

reducing substances subsequently shown by semiquantitative chromatography to be galactose (500 $\mathrm{mg} / 100 \mathrm{ml})$ and lactose $(200 \mathrm{mg} / 100 \mathrm{ml})$, but there was no galactosaemia.

Diarrhoea developed on the 17th day and persisted until death at age 33 days. The stool contained no reducing substances and the $\mathrm{pH}$ was never lower than 6 . The urinary pH remained high despite profound metabolic acidosis with persistently and slightly increased serum chloride levels of $107-108 \mathrm{mmol} / \mathrm{l}$. The gastrocolic reflex was noted 
to be very active. Institution of lactose-free feeds (Galactomin, Cow and Gate, Guildford, Surrey) had no effect on the frequency or consistency of the stools. It became impossible to maintain hydration; the baby became marasmic and developed generalised convulsions before she died.

Complement fixation tests for influenza A and B, para-influenza, adenovirus, respiratory syncytial virus, psittacosis, Q-fever, Mycoplasma pneumoniae cytomegalovirus, and Herpes simplex virus were negative. Rubella HA I was 128, Coxsackie $\mathbf{B}_{1-5}$ neutralisation tests were negative. Serum immunoglobulins were: IgG $350 \mathrm{mg} / 100 \mathrm{ml}, \mathrm{IgA}<40 \mathrm{mg} / 100$ $\mathrm{ml}, \mathrm{IgM}<8 \mathrm{mg} / 100 \mathrm{ml}$. Guthrie tests showed a fall of the tyrosine level from $20 \mathrm{mg} / 100 \mathrm{ml}(1.10 \mathrm{mmol} / \mathrm{l})$ on day 6 to $<2 \mathrm{mg} / 100 \mathrm{ml}(0 \cdot 11 \mathrm{mmol} / \mathrm{l})$ on the 21 st day. During this period the serum methionine level rose from $6(0.4 \mathrm{mmol} / \mathrm{l})$ to $20 \mathrm{mg} / 100 \mathrm{ml}(1 \cdot 34$ $\mathrm{mmol} / \mathrm{l})$ while urine amino-acid chromatography showed no abnormality on two occasions.

At necropsy the body weight was $1600 \mathrm{~g}$ and the immediate cause of death attributed to a massive gastrointestinal haemorrhage. The liver $(60 \mathrm{~g})$ had a coarsely lobulated surface with patchy bile staining, and appeared haemorrhagic. The extrahepatic biliary tract was patent to the duodenum. Other abnormalities included thymic atrophy $(<1 \mathrm{~g})$, abnormal lobulation of both lungs, and firm head of pancreas. The kidneys (combined weight $21 \mathrm{~g}$ ) and brain (220 g) appeared grossly normal. Histological examination showed extensive fibrosis of the liver with bile duct proliferation and irregular nodules of regenerating parenchyma which had undergone extensive necrosis. Giant cells were identified but not considered significant. There was haemosiderosis of the liver, exocrine pancreas, and thymus. The islets of Langerhans were increased in number but normal in size. There was acute papillary and tubular necrosis of the kidneys but no microcysts. The pancreas was not fibrosed and the histology of gastrointestinal tract, including the small intestine, appeared normal.

Case 2. In view of the outcome of the previous two pregnancies, amniocentesis was performed and showed normal galactose-1-phosphate uridyl transferase activity and a normal concentration of alphafetoprotein. In 1975 a boy was born with clinical features similar to those of Case 1 including large ears and a broad flat nose (Figs 1 and 2). The various findings are listed in the Table. At birth the baby weighed $1620 \mathrm{~g}$ at a gestational age estimated clinically and on ultrasonic fetal scanning to be 39 weeks. During the first few days of life he developed excoriated buttocks. On day 5 galactosuria was detected but no galactosaemia and he was given
Nutramigen (Mead Johnson Laboratories, Langley, Slough) and later Pregestimal (Mead Johnson Laboratories) for intermittent weight loss.

There was no serious concern until the 15 th day of life when he developed persistent watery diarrhoea which did not respond to feed changes or to periods of parenteral feeding. There followed episodes of serum electrolyte upset and acid-base imbalance. The baby became dehydrated and developed
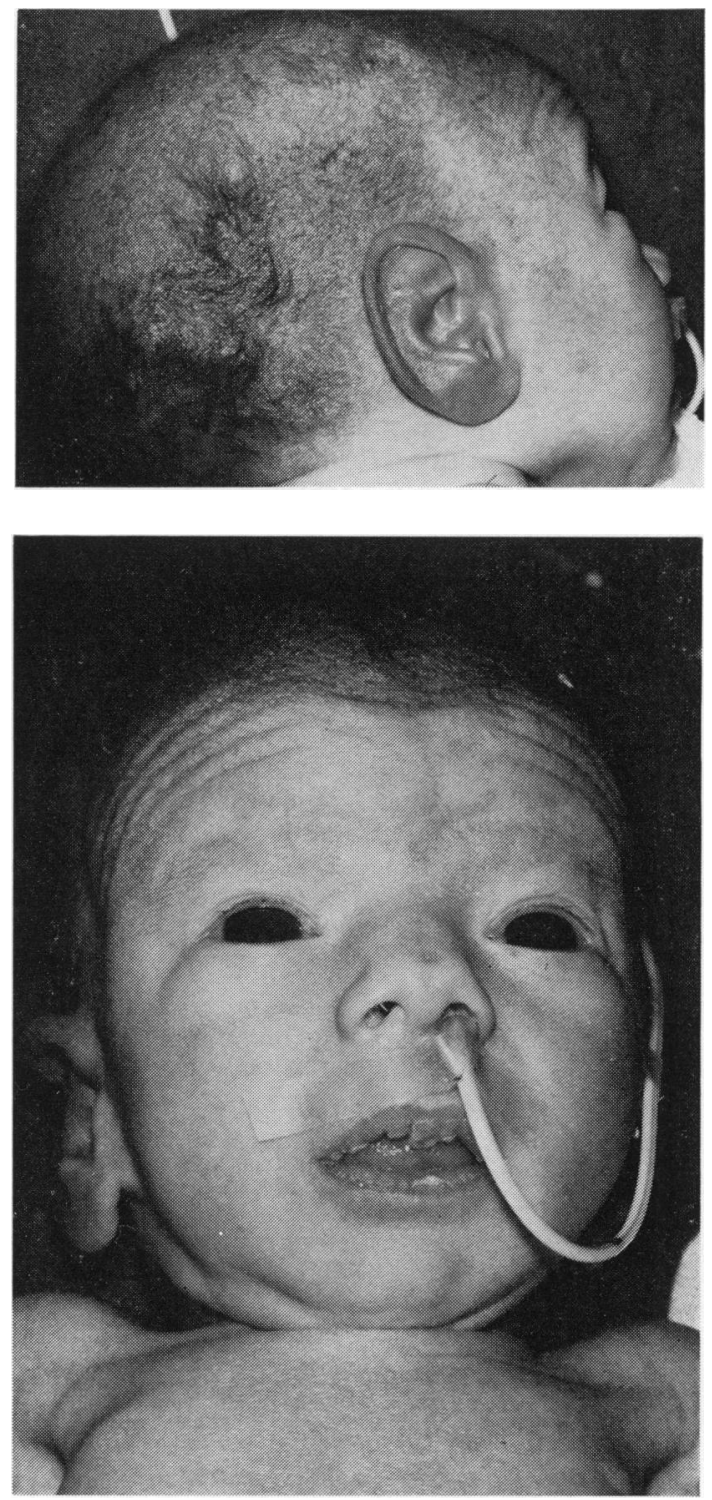

Figs 1 and 2 (Case 2.) Shows large, low set ears, flat broad nose, and large mouth. 
generalised convulsions before he died at 87 days. At no time were there signs of developmental retardation although periods of hyperactivity associated with prominent eyes suggested a diagnosis of neonatal hyperthyroidism.

Extensive investigations failed to show the cause of the child's illness. Porphobilinogen was found in the urine at age 6 days but could not be demonstrated subsequently. A Guthrie test at 6 days showed a tyrosine concentration of $20 \mathrm{mg} / 100 \mathrm{ml}$ but repeated plasma and urinary amino-acid chromatography produced normal patterns. Repeated blood counts showed a gradual and progressive anaemia with pyknocytosis and reticulocytosis; the baby was already receiving Ketovite (Paines and Byrne Ltd, Greenford, Middlesex), the daily dose of which contains $15 \mathrm{mg} \alpha$-tocopherol acetate.

In view of the galactosuria, red cell galactokinase and galactose-1-phosphate uridyl transferase activities were measured and were found to be normal.

The hepatic abnormalities in Case 1 and the finding of a palpable spleen in this baby prompted various investigations. Normal results were obtained for urinary glycosaminoglycans, leucocyte acid esterase, $\beta$-galactosidase, aryl sulphatase, hexosaminadase $A$ and $\alpha$-mannosidase, and plasma aryl sulphatase activities.

Total serum bilirubin levels did not rise above $33 \mu \mathrm{mol} / 1(1.9 \mathrm{mg} / 100 \mathrm{ml})$ and fasting total serum cholesterol was $2.3 \mathrm{mmol} / \mathrm{l}(88.8 \mathrm{mg} / 100 \mathrm{ml})$. Normal serum levels were obtained for calcium, magnesium, caeruloplasmin, immunoglobulins, alphafetoprotein, and $\alpha$-1-antitrypsin. Plasma ammonia lipoproteins and amino-acids were normal as were liver function tests.

Other normal findings included thyroid function tests (T3, T4, and TSH), sweat electrolytes, $x$-ray film of chest, barium meal and follow-through, electrocardiograms, chromosome analysis, viral and toxoplasma antibodies, and cultures of urine, blood, and cerebrospinal fluid. Normal values were found for urinary organic and phenolic acids and catecholamines, urinary and faecal porphyrins, and faecal fat concentration.

At necropsy the body weighed $2180 \mathrm{~g}$. The findings were similar to those of Case 1. The liver $(90 \mathrm{~g})$ was coarsely scarred and bile stained, but the extrahepatic biliary tract was patent. Apart from thymic atrophy $(4 \mathrm{~g})$ all other organs appeared grossly normal. Histological examination showed a cirrhotic liver with features similar to those of Case 1 but without acute parenchymal necrosis. Periportal haemosiderin was prominent and was also identified in the pancreas and spleen. The islets of Langerhans appeared increased in number as in Case 1. There were sparse microcysts of the distal collecting tubules of the kidneys. The brain histology was normal as was that of the bowel including the small intestine.

\section{Hair morphology and biochemistry}

Microscopy of scalp hairs. In both cases low-power light microscopical examination showed that the hairs varied in thickness and shape (aniso- and poikilotrichosis) and some were exceptionally fine. Many hairs were kinked. On high-power light microscopical examination the hairs were found to be deficient in substance, some appearing almost 'ghost-like'. At sites where hair was lacking in substance there were longitudinal breaks (trichoptilosis). In places the hair was twisted at regular intervals in its long axis (pili torti). All variations could be seen in individual hairs; loss of hair substance, partial breaks, and complete fractures. At fracture sites the ends were smooth (trichoschisis)

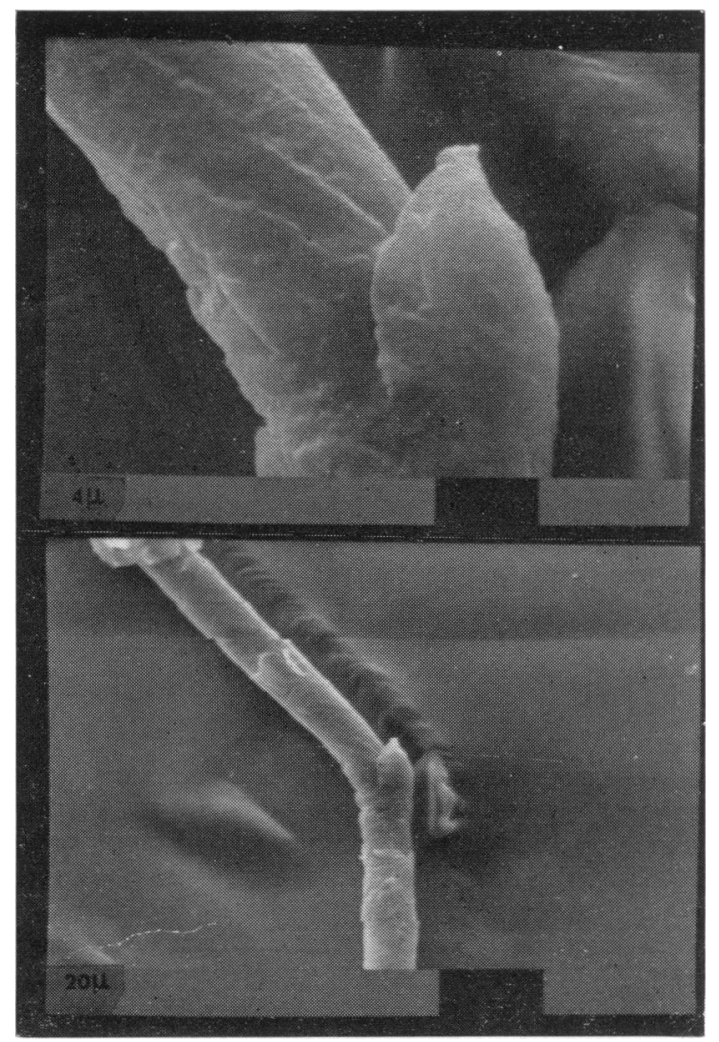

Fig. 3 Scanning electron microscopy of 'budding' of hair with loss of architecture (trichorrhexis blastysis) at low and high power. 
or brush-like (trichorrhexis nodosa). In addition, some hairs had a rope-like appearance and at places there were nodes through which oblique fractures were visible. Scalp hair from neither parent showed any abnormality.

Scanning electron microscopy. Scanning electron microscopy (Fig. 3) carried out under low power showed projections at multiple sites arising from the convex surface of a kinked hair. On higher magnification these projections had the appearance of buds for which the name trichorrhexis blastysis $(\mathrm{Gr}$ blastos = bud) is proposed. At affected sites the hair had lost its cuticle, the complete architecture was lost, and the hair was seen to break into parts.

Biochemistry of hair. Hair samples from the patients and their parents were analysed as described previously. ${ }^{2}$ The amino-acid composition of the parents' hair was normal and very similar to that of a sample of normal hair hydrolysed under the same conditions. Hair from both patients had a low cystine content and abnormal contents of several other amino-acids especially aspartate, proline, and leucine.

\section{Discussion}

The striking clinical features and abnormal histological and biochemical findings in the scalp hair of these siblings suggest that we are dealing with a hitherto undescribed syndrome. Abnormal facies, hepatic changes, and microcysts in the renal cortex in Case 2 are features seen in Zelweger's syndrome ${ }^{3}$ but the lack of cerebral changes, and the presence of marked diarrhoea, hyperactivity, and abnormal hair make this diagnosis unlikely. In addition, neither child showed the typical punctate epiphyseal calcification, and pipecolic acid could not be detected in 3 urine specimens from Case 2. The placental weight which was excessive both for birthweight and gestational age was not explained by rhesus incompatibility, congenital nephrotic syndrome, or by any other cause of hydrops fetalis.

The overall pattern of the biochemical abnormalities suggest a deficiency in high-sulphur protein fractions of the hair, similar, although somewhat less pronounced, than those reported in siblings with trichorrhexis nodosa with mental and physical retardation, ${ }^{4}$ in trichoschisis, ${ }^{5}$ and in the BIDS syndrome. ${ }^{6}$ Postnatal malnutrition may produce thinning of the hair shaft diameter ${ }^{7}$ and reduction in high sulphur proteins ${ }^{8}$ but does not present the microscopical hair features seen in our cases. The overall amino-acid analysis is a very imprecise indication of the composition of the complex mixture of keratins present in hair and the underlying protein abnormalities in these various disorders are unlikely to be identical.

Light microscopical examination of the hair in our two patients showed various abnormalities including pili torti and trichorrhexis nodosa, conditions which are found together in Menkes's syndrome, ${ }^{9}$ in arginosuccinicaciduria ${ }^{1}{ }^{10}$ and in the condition described by Tay. ${ }^{11}$ These conditions are excluded by the findings of normal serum copper in Case 2 and by normal urinary amino-acids on several occasions in both patients. The children with hair abnormalities described by Pollitt et al. ${ }^{4}$ differed from our patients in that they maintained good health.

We believe that our patients suffered from an abnormality hitherto undescribed, probably inherited as an autosomal recessive trait, and characterised by the features listed (Table). Exhaustive studies failed to find the cause of diarrhoea in these siblings and the biochemical abnormalities found in hair samples were not reflected in the blood or urine. The unique feature was the change in scalp hair noted on scanning electron microscopical examination which we have termed trichorrhexis blastysis. In the absence of any characteristic abnormality in blood chemistry and because biochemical analysis of hair is a difficult technique we recommend light and electron microscopical examination of hair as the diagnostic technique of choice.

R J P is a member of the external scientific staff of the Medical Research Council.

We thank Dr G Besley and Dr A Bain, Royal Hospital for Sick Children, Edinburgh, Dr J R Pincott and Prof. A D Patrick, The Hospital for Sick Children, London, Dr A P Mowat, King's College Hospital Medical School, London, Dr P J Snodgrass, University of Indiana, USA, and Dr E M Widdowson, University of Cambridge, for help with the investigations, and $\mathrm{Mr} \mathrm{N}$ Houston, Torry Research Station, Aberdeen, for carrying out the scanning electron microscopy.

\section{References}

1 Brown A C. Congenital hair defects. Third Conference on the Clinical Delineation of Birth Defects. Birth Defects 1971 ; No 8, 52-68.

2 Pollitt R J, Stonier P D. Proteins of normal hair and of cystine-deficient hair from mentally retarded siblings. Biochem J 1971; 122: 433-44.

3 Zelweger $H$. Cerebro-hepato-renal syndrome. In: Bergsma $\mathrm{O}$, ed. Birth defects compendium, second edition. London: Macmillan, 1979: 178-9.

4 Pollitt R J, Jenner F A, Davies M. Sibs with mental and 
physical retardation and trichorrhexis nodosa with abnormal amino acid composition of the hair. Arch Dis Child 1968; 43: 211-6.

5 Brown A C, Belser R B, Crounse R G, Wehr R F. A congenital hair defect: trichoschisis with alternating birefringence and low sulfur content. $J$ Invest Dermatol 1970; 54: 496-509.

- Baden H P, Jackson C E, Weiss L, et al. The physicochemical properties of hair in the BIDS syndrome. Am J Hum Genet 1976; 28: 514-21.

7 Baum J D, Hughes E A, Harris D A. Neonatal hair as a record of intra-uterine nutrition. Biol Neonate 1974; 25: 208-18.

8 Hartman D R, Fougere W, King K W. Diameter and aminoacid changes in hair of negro children with proteincalorie malnutrition. Proc Soc Exp Biol Med 1966; 123: $542-4$.

- Menkes J H, Alter M, Steigleder G K, Weakley D R, Sung J H. A sex-linked recessive disorder with retardation of growth, peculiar hair, and focal cerebral and cerebellar degeneration. Pediatrics 1962; 29: 764-79.

10 Allan J D, Cusworth D C, Dent C E, Wilson V K. A disease, probably hereditary, characterised by severe mental deficiency and a constant gross abnormality of aminoacid metabolism. Lancet 1958; i: 182-7.

11 Tay C H. Icthyosiform erythroderma, hair shaft abnormalities, and mental and growth retardation. A new recessive disorder. Arch Dermatol 1970; 104: 4-13.

Correspondence to Dr L Stankler, University of Aberdeen, University Medical Buildings, Foresterhill, Aberdeen AB9 2ZD.

Reprints will not be available.

Received 10 April 1981 